\title{
Use of Desalinated Reject Water as a Source of Magnesium for Phosphorus Recovery
}

\author{
Kazi P. Fattah, Sina Shabani, and Aqeel Ahmed
}

\begin{abstract}
In this study, the formation potential of struvite has been assessed using synthetic centrate mixed with reject water of a local desalination plant. $\mathrm{NH}_{4} \mathrm{H}_{2} \mathrm{PO}_{4}, \mathrm{MgCl}_{2} \cdot \mathbf{6} \mathrm{H}_{2} \mathrm{O}$, and $\mathrm{NH}_{4} \mathrm{Cl}$ were mixed in specific concentrations to simulate centrate of a wastewater treatment plant coming from centrifuge of anaerobic digesters. Due to the lack of adequate magnesium in domestic wastewater, the prepared synthetic centrate was further mixed with the reject water of MED and RO units of the desalination plant since it is rich in magnesium which is required for formation of struvite. Significant removal of phosphorus was observed through precipitation of phosphorus compounds after stirring the samples in a batch reactor.
\end{abstract}

Index Terms-Magnesium, phosphorus recovery, struvite, wastewater

\section{INTRODUCTION}

Phosphorus and nitrogen are considered as nutrients which are needed for living organisms to metabolize; however, excess amount of such nutrients can cause eutrophication of water bodies [1]. One of the primary sources of phosphorus in natural water bodies is through the effluent of the wastewater treatment plants; that is because human sewage contains high concentration of phosphorus. In wastewater treatment plants, especially those employing anaerobic digestion of their sludge or where enhanced biological phosphorus removal (EBPR) process is carried out typically have high levels of phosphorus within their treatment plant pipelines post dewatering facilities [2].The problem caused by excess amount of phosphorus in wastewater treatment plants is the formation of struvite (magnesium ammonium phosphate , $\left.\mathrm{MgNH}_{4} \mathrm{PO}_{4} \cdot 6 \mathrm{H}_{2} \mathrm{O}\right)$. Struvite is formed as white crystals that are made of equal molar concentrations of magnesium, phosphorous as well as ammonium $\left(\mathrm{MgNH}_{4} \mathrm{PO}_{4} \cdot 6 \mathrm{H}_{2} \mathrm{O}\right)$ [3]. The equation below represents the reaction that takes place in forming struvite.

$$
\mathrm{Mg}^{2+}+\mathrm{NH}_{4}^{+}+\mathrm{PO}_{4}{ }^{3-}+6 \mathrm{H}_{2} \mathrm{O} \rightarrow \mathrm{MgNH}_{4} \mathrm{PO}_{4} \cdot 6 \mathrm{H}_{2} \mathrm{O}
$$

Removal of phosphorus and ammonia is possible in the presence of magnesium through precipitation of struvite [4]. Under specific environmental conditions of temperature, $\mathrm{pH}$, alkalinity, phosphorous, ammonium and magnesium concentrations, struvite precipitation can be controlled.

With the advancement of treatment processes and the

Manuscript received April 15, 2013; revised May 30, 2013.

Kazi P. Fattah is with the College of Engineering, Department of Civil Engineering, American University of Sharjah.(e-mail: kfattah@ aus.edu) required discharge regulations in reduced phosphorus discharge to the water bodies, many wastewater treatment plants have secondary and tertiary phosphorus removal processes. The result is the increase in internal phosphorus concentrations, which has increased occurrences of struvite formation. The precipitation of struvite can lead to problems such as freezing of the valves, clogging of the pipes, and fouling of the pumps. Previous studies show that accumulation of struvite on pipe walls and equipment surfaces of anaerobic digestion significantly increases operational problems and maintenance costs of wastewater treatment plants [5] and [6]. The most common practice of removing uncontrolled formation of struvite is using concentrated acid solutions to be flushed through pipes, or in extreme cases of significant blockages due to struvite, the replacement of the entire section of affected pipeline [7]. One study shows that digested sludge pipe line's bore was reduced from 0.3 to 0.15 meter due to formation of struvite [8]. Another case shows that in 12 weeks, a $150 \mathrm{~mm}$ pipe made of rubber reduced to 60 $\mathrm{mm}$ in the discharge line of centrate [9]. Although struvite might be considered as a main problem occurring in wastewater treatment plants, it can be used in the production of fertilizers and soil conditioners [6]. There is a significant demand for phosphorus as a fertilizer for agricultural purposes. If phosphorus recovery happens in form of Struvite, it can be used as a slow-release fertilizer which will not leach like conventional fertilizers. In addition, struvite will remain on the soil for a notable period [10]. Struvite solubility should be minimal in order to remove struvite by precipitation, and higher $\mathrm{pH}$ values (8.0-9.0) minimize the solubility of struvite [3]. One study showed that initial $\mathrm{pH}$ of more than 8.1 was effective in formation of struvite [11]. Stirring and aeration will increase the $\mathrm{pH}$ of the solution through loss of $\mathrm{CO}_{2}$ which is a favorable condition for struvite formation [12]. The simplest methods for inducing struvite formation are controlling $\mathrm{pH}$ level and magnesium concentration [9]. The purpose of this research is to assess the formation potential of struvite by mixing synthetic centrate and reject water from desalination.

Magnesium plays a vital role in struvite precipitation. As shown in Table I, majority of previous studies on recovery of phosphorus used chemicals such as magnesium salts for their source of magnesium [13]-[17]. All these chemicals are not economically efficient. On the other hand, magnesium is lower in concentration in comparison to phosphorus and ammonia resulting in an excessive need of adding magnesium to reach the required equilibrium for precipitation of struvite [18]. One study shows that sea water can be a suitable source of magnesium for such experiments [19]; however, using membrane filtration can be another problem to cost 
effectiveness of the whole process. United Arab Emirates has $23 \%$ of the total production of desalinated water in the world [20]. Having the reject water from the desalination plant of, a rich and sustainable source of magnesium was used in this study which has almost no cost in comparison to previous sources of magnesium. In addition to a free source of magnesium, recovery of magnesium from the reject water will reduce the amount of magnesium that would otherwise have been discharged into the ocean.

\begin{tabular}{lll}
\multicolumn{2}{r}{ TABLE I: LiterATURE ON SOURCES OF MAGNESIUM AS A REAGENT } \\
\hline \hline No. & Source & Authors \\
\hline 1 & BMP $*^{*}$ & Quintana et al,2008[13] \\
2 & Magnesium Oxide & Quintana et al,2005[14] \\
3 & Magnesium Chloride $^{2}$ & Korchef et al, 2011[15] \\
4 & $\mathrm{MgCl}_{2} \& \mathrm{MgSO}_{4}$ & Hug et al, 2013[16] \\
5 & Magnesium Chloride $^{2}$ & M.I. Ali, 2007 [17] \\
\hline \hline
\end{tabular}

*Byproduct of Magnesium Production

\section{RESEARCH OBJECTIVES}

The purpose of this research is to assess the potential for phosphorus removal using desalinated reject water as a source of magnesium. The formation potential of struvite is assessed by mixing synthetic centrate and the reject water from a local desalination plant.

\section{MATERIALS AND METHODS}

\section{A. Preparation of Synthetic Feed and Magnesium Source}

Synthetic centrate samples were prepared to simulate the common values of phosphorus, nitrogen, and magnesium present in a centrate of anaerobic digester. The chemicals used and final targeted concentrations of the synthetic feed are shown in Table II. Desalination plant process reject water was used in the experiments for the source of magnesium. Reject water was collected from one of the multi-effect desalination (MED) and one reverse osmosis (RO) operating units at the water treatment plant. The concentration of magnesium in the MED and RO reject waters were $1555 \mathrm{mg} / \mathrm{L}$ and $2795 \mathrm{mg} / \mathrm{L}$, respectively.

TABLE II: CHEMICAL AND FINAL CONCENTRATIONS OF SyNTHETIC FEED USED IN THE EXPERIMENTS

\begin{tabular}{ll}
\hline \hline Chemical used & Final Targeted concentration \\
\hline$(\mathrm{NH} 4)_{2} \mathrm{HPO}_{4}$ & Phosphorus $-110 \mathrm{mg} / \mathrm{L}$ as $\mathrm{P}$ \\
$\mathrm{NH}_{4} \mathrm{Cl}$ & Ammonium $-1250 \mathrm{mg} / \mathrm{l}$ as N \\
$\mathrm{MgCl}_{2} \cdot 6 \mathrm{H}_{2} \mathrm{O}$ & Magnesium $-2 \mathrm{mg} / \mathrm{L}$ \\
\hline \hline
\end{tabular}

\section{EXPERIMENTAL APPROACH}

Synthetic centrate prepared in the lab was mixed with the reject water for and then samples were collected in 15 minutes intervals. The amount of reject water to be added was based on the Mg:P molar ratios of 2:1 and 8:1. Two $\mathrm{pH}$ set points were tested in the study -8.3 and 8.5 - the MED reject water.
These two numbers were chosen to minimize the need for high caustic addition but at the same time provide a $\mathrm{pH}$ environment high enough for struvite precipitation to occur. For the RO reject, the $\mathrm{pH}$ was lowered to 8.0 to as the magnesium concentration was significantly higher. Caustic solution $0.1 \mathrm{~N}$ was used to adjust the $\mathrm{pH}$ value of the mixed water to the desired $\mathrm{pH}$ set point. Samples were tested for phosphorus and magnesium concentrations. A summary of the conditions is provided in Table III.

TABLE III: SUMMARY OF EXPERIMENTAL CONDITIONS



\section{RESUlTS AND DisCUSSION}

\section{A. Influence of Reaction Time of Phosphorus Removal}

Results from Test 1 and 2 (Fig. 1) showed a decrease of $42.6 \%$ and $50 \%$, respectively, of phosphorus during the first 15 minutes of the experiment. No significant reduction in phosphorus was observed in continuing the tests beyond the first 15 minutes. Therefore, in order to reduce the removal process time, it is sufficient to carry out the process in short durations.

\section{B. Influence of pH on Phosphorus Removal}

Although the influence of $\mathrm{pH}$ on phosphorus removal is well documented [3], no significant difference in phosphorus removal was observed in the experiments. This could be due to the numerous "other" factors that strongly influence phosphorus removal via struvite precipitation. These factors, such as conductivity, may have contributed to diminishing reduction values. The influence of other factors in phosphorus removal is being investigated at present.

\section{Magnesium Recovery}

Fig. 2 shows the magnesium concentration levels before and after each trial of the experiments. For the first trial of the experiment initial magnesium of $338 \mathrm{mg} / \mathrm{L}$ reduced to 138 $\mathrm{mg} / \mathrm{L}$. In the second trial of the experiments after 15 minutes the magnesium concentration level went from 843 to 554 $\mathrm{mg} / \mathrm{L}$ and in the second 15 minutes it reduced further to 554 $\mathrm{mg} / \mathrm{L}$. It can be observed that significant magnesium is still left unused. One of the reasons for the low recovery could be the influence of other ions such as calcium and sodium, which are present in significant numbers in the reject water.

Table IV shows the results of the third trial in which $200 \mathrm{ml}$ was used as the synthetic feed mixed with $10 \mathrm{ml}$ of reject water from the reverse osmosis unit of the desalination plant to provide magnesium. The $\mathrm{pH}$ of the mixed sample was controlled at 8.0 in the beginning of the experiment using 0.1 $\mathrm{NaOH}$ solution. Samples were taken at the same time intervals of 15 and 30 minutes of mixing using a magnetic stirrer. The results showed $47.15 \%$ removal of phosphorus after 15 minutes followed by a further removal of $55.26 \%$ after 30 minutes of mixing. The entire experimental plan was the same 
for the fourth trial except the volume of reject water of reverse osmosis unit which was increased to $13 \mathrm{ml}$. Unlike what was expected, removal of phosphorus was not more efficient by increasing the volume of reject water by $3 \mathrm{ml}$. Results showed a percentage removal of $44.51 \%$ and $53.50 \%$ for 15 and 30 minutes of mixing time intervals, respectively. Other parameters checked are given in Table IV and Table $\mathrm{V}$ which are being used for further investigation of the results.

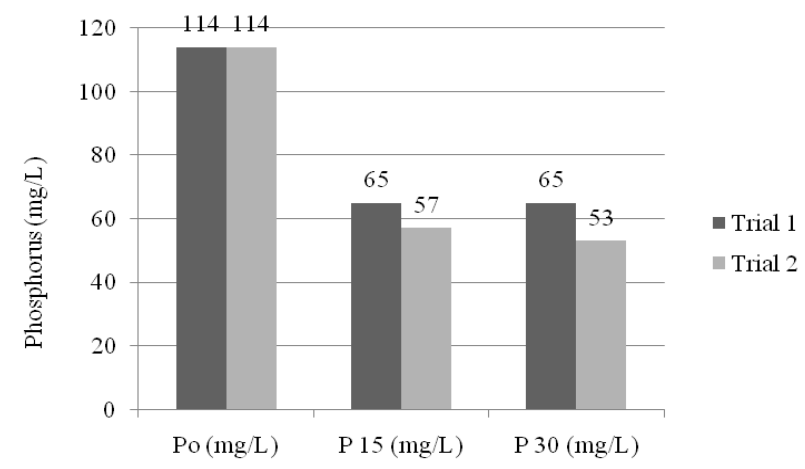

Fig. 1. Removal of phosphorus through precipitation

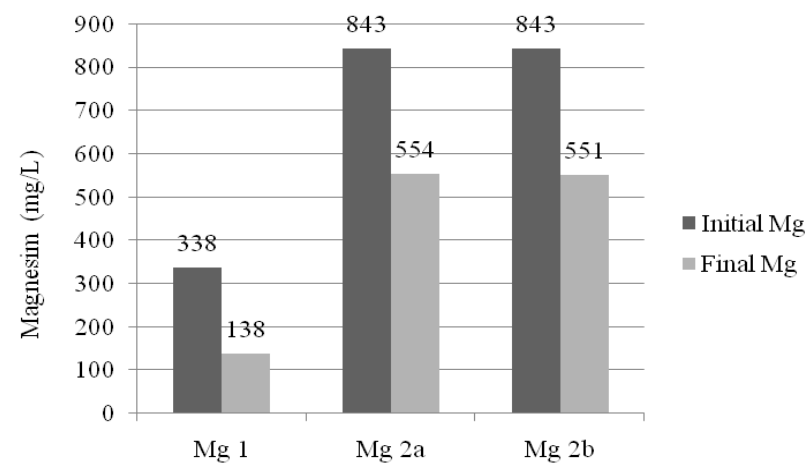

Fig. 2. Magnesium concentration through experiment

TABLE IV: RESULTS OF THIRD TRIAL

\begin{tabular}{lll}
\hline \hline Trial 3 & T15 & T30 \\
\hline Phosphorus & $60.25 \mathrm{mg} / \mathrm{L}$ & $51 \mathrm{mg} / \mathrm{L}$ \\
$\mathrm{pH}$ & 8.05 & 8.04 \\
Temperature & $23.8^{\circ} \mathrm{C}$ & $23.9{ }^{\circ} \mathrm{C}$ \\
Conductivity & $17.03 \mathrm{mS}$ & $17.00 \mathrm{mS}$ \\
TDS & $8.51 \mathrm{~g} / \mathrm{L}$ & $8.50 \mathrm{~g} / \mathrm{L}$ \\
Salinity & $10 \%$ & $10 \%$ \\
\hline \hline
\end{tabular}

TABLE V: RESULTS OF FOURTH TRIAL

\begin{tabular}{lll}
\hline \hline Trial 4 & T15 & T30 \\
\hline Phosphorus & $63.25 \mathrm{mg} / \mathrm{L}$ & $53 \mathrm{mg} / \mathrm{L}$ \\
$\mathrm{pH}$ & 8.06 & 8.04 \\
Temperature & $23.8^{\circ} \mathrm{C}$ & $23.8{ }^{\circ} \mathrm{C}$ \\
Conductivity & $18.43 \mathrm{mS}$ & $18.44 \mathrm{mS}$ \\
TDS & $9.22 \mathrm{~g} / \mathrm{L}$ & $9.22 \mathrm{~g} / \mathrm{L}$ \\
Salinity & $11 \%$ & $11 \%$ \\
\hline \hline
\end{tabular}

\section{CONCLUSION}

The recovery of phosphorus is essential for a sustainable future as it is used for the manufacturing of fertilizer and thus directly related to food production. Results of the experiments conducted in the present study showed that phosphorus recovery in form of struvite is applicable using two types of wastes - a synthetic centrate and desalinated reject water. Centrate of wastewater treatment plants and reject water of desalination plants can be mixed together under specific physical and chemical conditions in order to recover phosphorus through chemical precipitation of phosphorus. The cost of such a recovery of nutrient is significantly low since the materials used in these experiments are only wastes of wastewater and desalination treatment plants. This idea can be a huge step forward to the concepts of sustainability and zero waste. For future research ideas some parameters like temperature, $\mathrm{pH}$, calcium effect, and reject water of other desalination methods can be analyzed under the same experimental conditions

\section{REFERENCES}

[1] D. M. Anderson, J. M. Burkholder, W. P. Cochlan et al., "Harmful algal blooms and eutrophication: Examining linkages from selected coastal regions of the United States," Harmful Algae, vol. 8, pp. 39-53, 2008.

[2] M. Marti, A. Bouzas, A. Seco, and J. Ferrer, "Struvite precipitation assessment in anaerobic digestion processes," Chemical Engineering, vol. 141, pp. 67-74, 2008.

[3] K. P. Fattah, D. S. Mavinic, F. A. Koch, and C. Jacob, "Determining the feasibility of phosphorus recovery as struvite from filter press centrate in a secondary wastewater treatment plant," Journal of Environmental Science and Health: Part A. vol. 43, no. 7, pp. $756-$ 764, 2008

[4] A. Korchef, H. Saidou, and M. Ben Amor, "Phosphate recovery through struvite precipitation by $\mathrm{CO}_{2}$ removal: Effect of magnesium, phosphate and ammonium concentrations," Journal of Hazardous Materials, vol. 186, pp. 602-613, 2011.

[5] K. N. Ohlinger, T. M. Young, and E. D. Schroeder, "Predicting struvite formation in digestion," Water Research, vol. 32, no. 12, pp 3607-3614, 1998.

[6] M. Quintana, E. Sancheza, M. F. Colmenarejoa, J. Barrera, G. Garcia, and R. Borja, "kinetics phosphorus removal and struvite formation by the utilization of byproduct of magnesium oxide production," Chemical Engineering, vol. 111, pp. 45-52, 2005.

[7] J. D. Doyla, K. Oldring, J. Churchley, and S. A. Parsons, "Struvite formation and the fouling propensity of differen materials," Water Research, vol. 36, pp. 3971-3978, 2002.

[8] Y. J. Shao, F. Wada, V. Abkian, J. Crosse, B. Horenstein, and D Jenkins, "Effects of MCRT on enhanced biological phosphorus removal," Water Science Technology, vol. 26, pp. 967-976, 1992.

[9] J. D. Doyle, R. Philip, J. Churchley, and S. A. Parsons, "Analysis of struvite precipitation in real and synthetic liquors," Saf Environ Prot, vol. 78, pp. 480-488, 2000.

[10] L. E. De-Bashan and Y. Bashan, "Recent advances in removing phosphorus from wastewater and its future use as fertilizer," Water Research, vol. 38, no. 19, pp. 4222-4246, 2003.

[11] H. Saidou, A. Korchef, S. Ben Moussa, and M. Ben Amor, "Struvite precipitation by the dissolved $\mathrm{CO} 2$ degasification technique:Impact of the airflow rate and pH," Chemosphere, vol. 74, pp. 338-343, 2009.

[12] K. P. Fattah, N. Sabrina, D. S. Mavinic, and F. A. Koch. "Reducing operating costs for struvite formation with carbon dioxide stripper," Water Science and Technology, vol. 58, no. 4, pp. 957 - 962, 2008.

[13] M. Quintana, M. F. colmenarejo, J. Barrera, E. Sanchez, G. Garcia, L. Traviesco, and R. Borja, "Removal of phosphorus through precipitation using a by-product of magnesium oxide production(BMP): Effect of the mode of BMP preparation," Chemical Engineering Journal, vol. 136, pp. 204-209, 2008.

[14] M. Quintana, E. Sanchez, M. F. Colmenarejo, J. Barrera, G. Garcia and R. Borja, "Kinetics of phosphorus removal and struvite formation by utilization of by-product of magnesium oxide production," Chemical Engineering Journal, vol. 111, pp. 45-52, 2005.

[15] A. Korchef, H. Saidou, and M. Ben Amor, "Phosphate recovery through struvite precipitation by $\mathrm{CO}_{2}$ removal: Effect of magnesium, phosphate and ammonium concentrations," Journal of Hazardous Materials, vol. 186, pp. 602-613, 2011.

[16] A. Hug and K. M. Udert, "Struvite precipitation from urine with 
electrochemical magnesium dosage," Water Research, vol. 47, pp. 289-299, 2013

[17] M. I. Ali, "Struvite crystallization in fed-batch pilot scale and description of solution chemistry of struvite," Chemical Engineering Research and Design, vol. 85, pp. 344-356, 2007.

[18] G. El Diwani, Sh. El Rafie, N. N. El Ibrari, and H. I. El Aila, "Recovery of ammonia nitrogen from industrial wastewater treatment as struvite slow releasing fertilizer," Desalination, vol. 214, pp. 200-214, 2007.

[19] O. Lahav, M. Telzhensky, A. Zewhn, Y. Gendel, J. Gerth, W. calman, and L. Birnhack, "Struvite recovery from municipal -wastewater sludge centrifuge supernatant using seawater NF concentrate as a cheap MG(II) source," Separation and Purification Technology, vol. 108, pp. 102-110, 2013.

[20] S. Lattemann and T. Hopner, "Environmental impact assessment of seawater desalination," Desalination, vol. 220, pp. 1-15, 2008.



Kazi P. Fattah received his Ph.D degree in civil engineering (Environmental Discipline) from the University of British Columbia. Vancouver, B.C., Canada. 2010, and M.A.Sc. in civil engineering (Environmental Discipline), from the University of British Columbia, Vancouver, B.C., Canada, 2004. $\mathrm{He}$ earned his B.Sc. degree in civil engineering. Bangladesh University of Engineering and Technology, Dhaka, Bangladesh, 2001.

$\mathrm{He}$ is currently an assistant professor at the American University of Sharjah, Sharjah, U.A.E. He has also worked as a consultant at Associated Engineering, Burnaby, B.C., Canada and as an independent consultant to Metro Vancouver. He was a Visiting Assistant Professor at The University of British Columbia. He is actively involved with nutrient removal and recovery from wastewater, sustainable treatment options and water reuse.



Sina Shabani earned his B.Sc degree in civil engineering, American University of Sharjah, UAE 2011.

$\mathrm{He}$ is currently enrolled in the master's program of American University of Sharjah. In spring 2011 he was awarded graduate teaching/research assistant position in the university. He has been involved in research and laboratory work since he was selected to be in charge of the responsibilities given to him as an assistant.

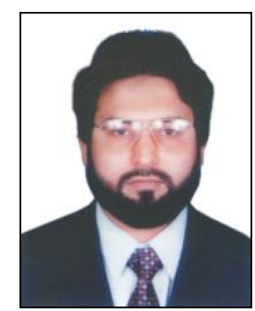

Aqeel Ahmed earned his M.Tech degree in civil engineering (Geotechnical), Jawaharlal Nehru Technological University at Hyderabad, India. 1993, and $\mathrm{BE}$ in civil engineering, Osmaina University at Hyderabad, India. 1987.

He has been with American University of Sharjah since 2000. He is currently working as Instructor of Civil Engineering. He has over 26 years of working experience in academia and industry. He has been working with multi-disciplinary fields of geo-technical, structural, and environmental engineering including software development, web designing, development, supervision of civil engineering laboratories and earthquakes monitoring systems. His areas of research are problems related to geo-environmental issues, soil-structure interaction, earthquake engineering and Computer Applications in Civil Engineering. 